\title{
Rats show no preference between free and earned water in an advance-response procedure
}

\author{
ROBERT E. DeLONG and MICHAEL G. GRISHAM \\ University of Iowa, Iowa City, Iowa 52242
}

\begin{abstract}
Although an arbitrarily specified instrumental response may persist when free reinforcers are concurrently available, the interpretation that earned reinforcers are preferred is tenuous. The present advance-response procedure used both time allocation and advance response rates as indices of preference between free and earned water in rats. When multiple schedule components were two response-dependent schedules with different overall reinforcement rates, higher rates of reinforcement were preferred. However, when the multiple schedule consisted of response-dependent and response-independent components equated for overall rates of reinforcement, no consistent preference for free or earned reinforcers was evident. That a preference for free reinforcers was not obtained is difficult to reconcile with concepts of least effort.
\end{abstract}

Most contrafreeloading procedures involve the persistence of a particular reinforced response (e.g., barpressing or keypecking) despite continuous free access to identical reinforcers (usually food or water) in a container placed in the experimental chamber (cf. Jensen, 1963). There is no question that, in a variety of experimental settings, animals will earn reinforcers when identical free reinforcers are continuously accessible (cf. Osborne, 1977). This phenomenon connotes two separate, but related, issues (cf. D'Amato, 1974; Osborne, 1977; Taylor, 1972). First, under what conditions will animals work for reinforcers when free reinforcers are available? Second, do animals prefer earned reinforcers? The present paper deals with the latter question.

To assess an animal's preference with regard to a particular variable, it is necessary to devise an explicit choice procedure in which two or more experimental conditions, differing only in terms of the variable in question and stimuli that signal the different conditions, are pitted against one another. That is, the procedure must put the subject in a situation involving choice between at least two discriminable conditions, where the variable being considered forms the only basis for the subject's choice. Preference, then, is expressed in terms of differential allocation of responses or time by the subject to the different experimental conditions.

This report is based on a portion of a thesis submitted by the first author to the Graduate College of The University of Iowa in partial fulfillment of the requirements for an MA degree. The research was supported by Biomedical Sciences Support Grant FR-07035 awarded to The University of Iowa by the National Institute of Mental Health. We wish to thank Jim Deich, Gary Lucas, Keith Nelson, and Ed Wasserman for their suggestions for revising this manuscript. Reprints may be obtained from Robert E. Delong, Department of Psychology, University of Iowa, Iowa City, Iowa 52242. M. G. Grisham is now at Bell Laboratories.
If these criteria are applied to the general procedure of giving the subject a choice between obtaining reinforcers from a container that is continuously available and performing an experimenter-designated response for a single reinforcer, it becomes readily apparent that the procedure is unable to provide an unconfounded measure of preference between free and earned reinforcers. Because the subject is confronted with a choice between alternatives that may differ in several ways-instrumental response topography, ambient stimulus conditions that accompany reinforcer delivery, maximum rate of reinforcement attainable, and requisite effort for approach and consumption-the measure of preference obtained could reflect any one, or a combination of several, of the discrepant variables.

To date, two research strategies have been employed to control for the above differences: (1) allowing subjects a choice between responding for reinforcers in one compartment of a two-compartment experimental chamber or receiving free reinforcers at the same overall rate of delivery in the other compartment (Morgan, 1974; Singh, 1970, 1972a, 1972b; Singh \& Query, 1971); and (2) exposing subjects to a concurrent chains procedure (cf. Autor, 1969) in which reinforcers can be earned in the terminal link of one chain and free reinforcers are delivered at the same overall rate, independent of responding, in the terminal link of the other chain (Brinker \& Treadway, 1975; Halliday \& Boakes, 1972; Killeen, 1968; Moore \& Fantino, 1975; Neuringer, 1969). Studies using a two-compartment procedure have yielded conflicting results: Morgan's experiments showed a preference for free reinforcers, while Singh's experiments produced a preference for earned reinforcers. In general, the results of studies using a concurrent chains procedure have found that animals show no preference between free and earned reinforcers. The pres- 
ent experiment used still another explicit choice procedure-an advance-response procedure (cf. Honig, Beale, Seraganian, Lander, \& Muir, 1972)-to provide further data for the issue of free vs. earned preference.

In an advance-response procedure, subjects are provided with a response that, when acquired, allows them to terminate the current component of a multiple schedule and present the next component in a preprogrammed series. Thus, by differentially emitting the advance response, subjects are able to spend most of the experimental session in the preferred component of a multiple schedule. In the present context, the advance-response paradigm offers the following advantages: (1) Because free and earned reinforcers are delivered into the same container, the response topographies required for approach and consumption are identical for both conditions. That is, the responses required to earn a reinforcer and to freeload can be specified in terms of relative effort because they are identical except for an additional response requirement in the earned condition. (2) Only the stimulus that signals whether the free or earned condition of the multiple schedule is in effect changes, so the ambient stimulus conditions accompanying reinforcer delivery do not confound the results obtained. (3) The components of the multiple schedule, between which the subject is free to allocate time, can be devised so as to equate the rates of reinforcement. (4) Both amount of advance responding and time allocation in each component schedule may be used as measures of preference. (5) The advance-response procedure requires no unusual apparatus. It can be arranged in an ordinary Skinner box that has two response manipulanda, a reinforcer dispenser, and a discriminable experimenter-controlled stimulus.

In the present experiment, the advance-response contingency was superimposed on three different multiple schedules. The component schedules will be unfamiliar to the reader, so a description of the rationale for each of the experimental groups is provided here. The multiple schedule of primary interest consisted of a response-independent component scheduled in much the same way as a random time (RT) schedule ("free" or F) and a second component programmed in much the same way as an alternative random interval random time (alt RI RT) schedule ("free/earned" or F/E). These particular schedules were used because they allow the experimenter to equate overall rates of reinforcement in the two components. The multiple F/E F schedule provided a situation where the only differences between the two schedule components were the opportunity to earn a reinforcer in the $\mathrm{F} / \mathrm{E}$ schedule and the discriminative stimulus. Since rats earn almost all reinforcers on a $\mathrm{F} / \mathrm{E}$ schedule (Walker \&
Grisham, Note 1), a multiple F/E F schedule affords a suitable baseline for testing preference between free and earned reinforcers. The second multiple schedule consisted of two F/E components, where the only differences between the schedule components were the overall reinforcer frequency and the discriminative stimulus. Since results from W. K. Honig's laboratory have indicated that pigeons exhibit a preference for variable interval schedules over extinction in an advance-response procedure (Honig \& Beale, 1976; Honig et al., 1972; Honig \& Lindsey, 1975; Leyland \& Honig, 1975; Siegel \& Honig, 1970; Honig \& Seraganian, Note 2), it was reasoned that schedules with large differences in the overall rate of reinforcement would afford an adequate baseline to determine whether the present advance-response procedure provided a means by which to measure preference in rats. Finally, a multiple schedule with the same F/E schedule in effect for both components was included to insure that any obtained preferences were not confounded by preference for a particular discriminative stimulus.

\section{METHOD}

\section{Subjects}

Thirty-six experimentally naive male hooded rats from the colony of the Department of Psychology at The University of Iowa were used as subjects. They were approximately 120 days old at the start of the experiment and were housed individually in $24 \times$ $18 \times 18 \mathrm{~cm}$ cages with $24-\mathrm{h}$ light. Throughout the experiment, the subjects were maintained at $75 \%-80 \%$ of their free-feeding weights by being deprived of water. Weight was allowed to increase $1 \mathrm{~g}$ per day until subjects were 150 days old, and then was held constant for the remainder of the experiment. The subjects were weighed prior to each daily session and were given whatever supplemental water was necessary (usually $15-20 \mathrm{ml}$ ) at the conclusion of each session. Two subjects were replaced during the course of the study, one because it died and the other because it stopped responding. Another animal died late in the study and was not replaced.

\section{Apparatus}

Six identical $30 \times 22.5 \times 25 \mathrm{~cm}$ chambers were used for pretraining and choice. The two side walls and the lid of the chambers were made of $.65-\mathrm{cm}$ clear Plexiglas, and the end walls were constructed of $.16-\mathrm{cm}$ aluminum sheet. The floor consisted of $.64-\mathrm{cm}$ stainless steel rods spaced $1.59 \mathrm{~cm}$ apart, center to center. The Plexiglas sides of the chambers were lined with $.16-\mathrm{cm}$ aluminum sheet. Two manipulanda were present in each chamber. One manipulandum, a .64-cm-diam stainless steel bar, was located in the center of one end wall $5.08 \mathrm{~cm}$ above the grid floor and projected $2.54 \mathrm{~cm}$ into the chamber. A force of $.08-.10 \mathrm{~N}$ was required to operate the bar switch. A second manipulandum, a stainless steel link chain, was located $1.59 \mathrm{~cm}$ out from the wall containing the bar and $4.45 \mathrm{~cm}$ to the left of the bar. This chain was attached to a switch on the lid and hung $12.7 \mathrm{~cm}$ into the chamber. A $2.54-\mathrm{cm}$-diam stainless steel ring, the bottom of which was $10.2 \mathrm{~cm}$ above the grid floor, was attached to the end of the chain. A force of .13-.15 $\mathrm{N}$ was required to operate the chain switch.

Each chamber was located in a $63.5 \times 34.3 \times 34.9 \mathrm{~cm}$ soundattenuating Coleman chest. The lids of these enclosures had 1.27$\mathrm{cm}$-diam viewers to permit observation of subjects during experimental sessions. The chambers were ventilated by externally mounted blowers which, in addition to speakers that supplied 
70-dB white noise, provided masking noise. During testing, the chambers were either dark or illuminated by GE1 829 bulbs at $24 \mathrm{~V} \mathrm{de}$ mounted outside the chamber proper, $15.5 \mathrm{~cm}$ from the lid and $6.5 \mathrm{~cm}$ from the wall containing the lever. The reinforcer was $.1 \mathrm{ml}$ of water delivered into a $3-\mathrm{cm}$-deep stainless steel compartment that was accessible via a $3.5-\mathrm{cm}$-diam hole centered in the wall $3 \mathrm{~cm}$ directly above the bar. Experimental control and data collection were managed from a separate room by a PDP-8/F computer (Digital Equipment Corporation) using the SKED software system (Snapper, Stephens, \& Lee, Note 3) to control a solid-state interface (Grisham \& Frei, 1977).

\section{Procedure}

Pretraining. Prior to instituting choice conditions, the chainpull response was shaped by successive approximation in 18 randomly selected rats and the barpress response was shaped in the 18 remaining rats. The response shaped was designated as the subject's instrumental response. Once an animal earned 60 reinforcers in less than $20 \mathrm{~min}$, the shaping phase of training was complete. This phase of the experiment took 2 weeks, with subjects requiring two to four sessions to reach criterion. Animals that finished shaping early were maintained in their home cages until shaping had been completed for all subjects. Then all subjects were trained for 3 more days on a fixed-ratio 1 schedule of reinforcement with a limit of 60 reinforcers per day.

Schedules. Figure 1 illustrates the schedules that formed the different experimental conditions. A "free" (F) schedule is a responseindependent schedule programmed in much the same way as a RT schedule. That is, a probability generator is sampled periodically to determine if a reinforcer will be delivered. In this case, a reinforcer was delivered independently of responding with a probability of .5 every $30 \mathrm{sec}$. This particular schedule was called an F 1-min schedule because, on the average, reinforcers were delivered once per minute. The only unusual feature of the present F 1-min schedule was that once a reinforcer was set up, reinforcer delivery was delayed for $15 \mathrm{sec}$. The rationale for this delay will become clear as the other schedules are described.

A "free/earned" (F/E) schedule is identical to an F schedule except that subjects have the opportunity to earn a reinforcer during the $15 \mathrm{sec}$ preceding response-independent delivery of the reinforcer. If a subject on an $F / E$ schedule responded during this 15 -sec reinforcer delivery period, indicated by the hatched areas of Figure 1, its first response was followed immediately by water delivery and reinforcer availability terminated at once (see $A$ or D). That is, only the first response during the 15-sec delivery period was reinforced; subsequent responses during that $15 \mathrm{sec}$ were not reinforced (see C). At the end of a $15-\mathrm{sec}$ reinforcer delivery period, water was delivered freely only if the subject had not already earned a reinforcer (see B). Thus, a reinforcer could be either earned or obtained freely on an F/E schedule, and, on the average, reinforcers were delivered at the same rate as on a comparable $F$ schedule whether the subject responded or not. In the present study, different $F / E$ schedules were formed by

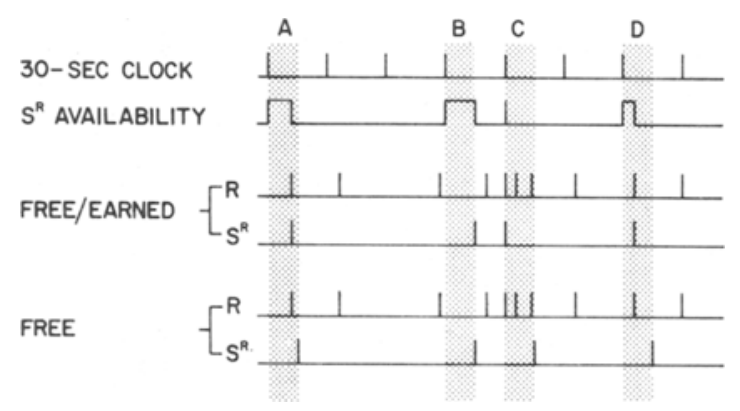

Figure 1. A schematic representation of "free/earned" and "free" schedules of reinforcement (see text). changing the probability with which a reinforcer delivery period was set up every $30 \mathrm{sec}$. An F/E 1-min schedule, which delivered reinforcers at the same average rate as an F 1-min schedule, was programmed by sampling with a probability of .5 every $30 \mathrm{sec}$. An F/E 5-min schedule was programmed by sampling with a probability of 11 every $30 \mathrm{sec}$.

Experimental conditions. Six rats from each instrumental response condition were randomly assigned to each of three experimental conditions: a multiple F/E 1 -min $\mathrm{F} 1$-min schedule, a multiple F/E 5-min F/E 1-min schedule, or a multiple F/E 1$\min F / E$ 1-min schedule. All three multiple schedules consisted of two 2-min components that were cued by chamber illumination conditions and occurred in strict alternation. That is, one schedule component and its corresponding chamber illumination were presented automatically after the other component had been in effect for $2 \mathrm{~min}$. The $\mathrm{F}$ component of the multiple F/E 1-min F 1-min schedule was always cued by chamber darkness, as was one of the $\mathrm{F} / \mathrm{E}$ components of the multiple F/E 1-min F/E 1-min schedule and the F/E 1-min component of the multiple F/E 5-min F/E 1 -min schedule. Each session lasted $60 \mathrm{~min}$.

Choice. Throughout choice testing, a barpress served as an advance response for subjects that had chainpulling designated as the instrumental response (bar advance), while a chainpull served as an advance response for subjects that had barpressing as the instrumental response (chain advance). Each advance response, except those occurring within $5 \mathrm{sec}$ after an effectual advance response or a programmed component change, terminated the prevailing component and its associated chamber illumination and produced the other component schedule. Thus, by acquiring ladvance responding, the subjects were able to control which schedule component was usually in effect. The 5 -sec periods where advance responses had no effect were instituted to increase the likelihood that subjects would attend to the experimental condition before advancing out of it and to prevent bursts of responding from causing multiple advances.

Behavioral measures. The three dependent variables of primary interest were time allocated to each component of the multiple schedules, the amount of advance responding in each component of the multiple schedules, and the rate of instrumental responding in each component of the multiple schedules. The first two dependent variables, time allocation and advance response rates, provided indices of preference between the two multiple schedule components. If no preference was obtained, time spent in each component of a multiple schedule would be $1,800 \mathrm{sec}$ (i.e., equal allocation) and the rates of advance responding would be the same (and probably very low) in both schedule components. Instrumental response rates in the multiple schedule components simply indicated whether subjects discriminated between components. The number of reinforcers obtained in each component was also recorded.

\section{RESULTS}

Since the results were generally the same across responses, the data that follow consist of averages between bar and chain advance groups.

\section{Instrumental Response Rates}

Figure 2 shows that rates of instrumental responding differed for the two schedule components in both $\mathrm{F}$ / E1-F1 and F/E5-F/E1 groups, but instrumental response rates were essentially the same for the two F/E 1-min components of the F/E1-F/El control group. Thus, both experimental groups discriminated between schedule components, a prerequisite to exhibiting a preference. 


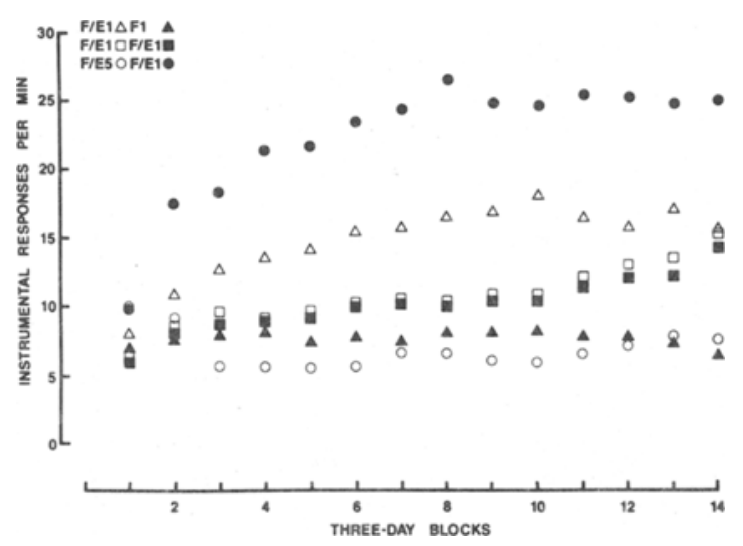

Figure 2. Mean instrumental response rates over 3-day blocks.

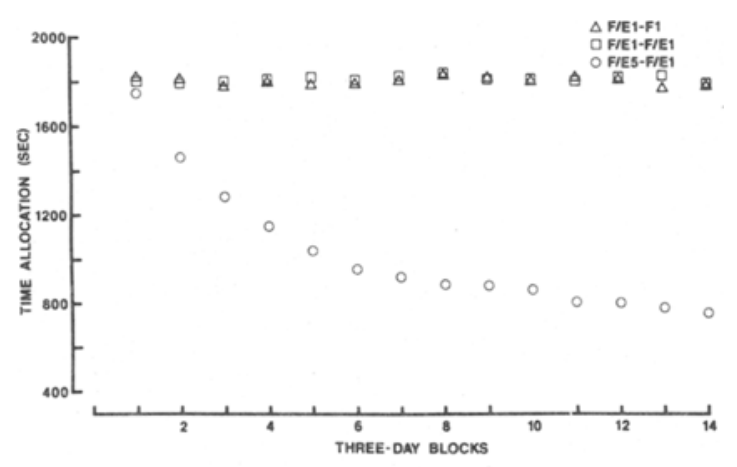

Figure 3. Mean time (in 3-day blocks) allocated to the component that occurred when the chamber was illuminated (F/E $1 \mathrm{~min}$, F/E $1 \mathrm{~min}$, and F/E $5 \mathrm{~min}$ for the F/E1-F1, F/E1-F/E1, and F/ E5-F/E1 groups, respectively). (1,800 indicates that subjects spent an equal amount of time in both schedule components.)

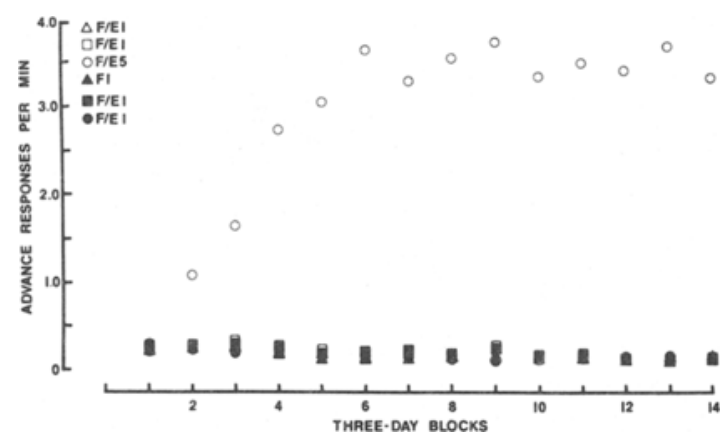

Figure 4. Mean advance response rates over 3-day blocks.

\section{Time Allocation}

Figure 3 shows that $F / E 1-F / E 1$ and F/E1-F1 groups spent about the same amount of time in their respective schedule components, while F/E5-F/E1 groups eventually spent much more time in the F/E 1min component. That is, only subjects in the F/E5F/E1 groups exhibited a preference between schedule components, preferring the schedule with a higher reinforcer frequency. Because the schedules in effect in both components of the multiple F/E 1-min F/E 1-min schedule were the same, differential time allocation in F/E1-F/E1 groups would have indicated a preference for either light or dark. Since the stimulus conditions accompanying multiple schedule components were not counterbalanced, it is important that no such difference was obtained.

\section{Advance Response Rates}

Figure 4 shows that rates of advance responding were very low except in the $\mathrm{F} / \mathrm{E} 5$-min component of the multiple F/E 5-min F/E 1-min schedule. Again, these results indicate that only subjects in the F/E5-F/E1 groups showed a preference between schedule components.

Table 1 shows the overall rates of reinforcer delivery for the different schedules. As expected, the components of the F/E 1-min F/E 1-min schedule delivered reinforcers at about the same rate. However, the F/E 1-min and F 1-min components of the multiple F/E 1-min F 1-min schedule did not. Reinforcers were delivered at a slightly higher rate in the F/E 1-min component. This difference can be accounted for by closely examining the two schedules. If a subject advanced out of the $F$ component during the $15 \mathrm{sec}$ prior to a scheduled reinforcer delivery, that reinforcer was lost. This was also true for the F/E component, provided the subject had not performed the instrumental response first. That is, in the F/E component it was possible for the subject to earn a reinforcer (during a 15 -sec reinforcer delivery period) and then advance out of the $\mathrm{F} / \mathrm{E}$ schedule, thus obtaining a reinforcer that would have been lost under similar circumstances in a F schedule.

That reinforcers could be lost by advancing out of a $\mathrm{F} / \mathrm{E}$ reinforcer delivery period prior to making an instrumental response may account for the fact that the differences in reinforcement rates were slightly higher than five to one for the components of the multiple F/E 5-min F/E 1-min schedule (see Table 1). Specifically, animals were advancing out of the $\mathrm{F} / \mathrm{E}$ 5-min component much more frequently than they were advancing out of the F/E 1-min component.

Table 1

Overall Rates of Reinforcement for the Components of Different Multiple Schedules

\begin{tabular}{llccccc}
\hline & & \multicolumn{2}{c}{ Bar Advance } & & \multicolumn{2}{c}{ Chain Advance } \\
\cline { 3 - 4 } & & $\begin{array}{c}\text { Rein- } \\
\text { forcers }\end{array}$ & SE & & $\begin{array}{c}\text { Rein- } \\
\text { forcers }\end{array}$ & SE \\
\hline F/E1-F1 & F/E1 & .9367 & .0083 & .9679 & .0089 \\
& F1 & .8521 & .0090 & .8600 & .0149 \\
F/E1-F/E1 & F/E1 & .9360 & .0095 & .9564 & .0107 \\
& F/E1 & .9317 & .0097 & .9438 & .0106 \\
F/E5-F/E1 & F/E5 & .1483 & .0073 & .1850 & .0048 \\
& F/E1 & .9526 & .0070 & .9681 & .0061 \\
\hline
\end{tabular}

Note-Reinforcers are given in reinforcers per minute. 
Therefore, reinforcers could have been lost more frequently by advancing out of availability periods that occurred during the F/E 5-min component, despite the fact that, on the average, availability periods were five times more frequent in the $F / E$ 1-min component.

\section{DISCUSSION}

The present experiment demonstrates that rats discriminate between components of a multiple F/E 1-min F 1-min schedule, but show no preference for either earned or free reinforcers. Differences in time allocation and advance response rates between components of the multiple F/E 5-min F/E 1-min schedule indicate that the advance-response procedure is sensitive to differences in overall reinforcer frequency in rats. Therefore, the present results indicate that in advance-response procedure can provide a means of measuring preference in rats. But, if a preference exists between free and earned reinforcers, it is too small to be detected with the advanceresponse procedure used here.

The present lack of preference between free and earned reinforcers replicates those studies cited earlier using a concurrent chains procedure. That a similar finding was obtained with two different procedures argues against the null result being due to a procedural artifact. While it is true that conflicting results have been obtained using a two-compartment procedure, it should be noted that experiments using such a procedure have failed to equate the stimulus conditions accompanying reinforcer delivery in the free and earned compartments: The bar was present in the earned condition and retraced in the free condition. Although there is no direct evidence that contact with or sight of the bar acted as a conditioned reinforcer, given the bar's temporal contiguity with reinforcement, the possibility remains that it did. The combined reinforcing value of this conditioned reinforcement and the primary reinforcement could account for the results of Singh's experiments, which constitute most of the data available. The results of a two-compartment study that left the response manipulandum in both compartments would certainly be interesting.

A lack of preference between free and earned reinforcers not only questions interpretations of the contrafreeloading phenomenon as an indication that animals prefer earned to free reinforcers (e.g., Carder \& Berkowitz, 1970; Jensen, 1963), but also questions the more general behavioral concepts of least effort (e.g., Hull, 1943; Logan, 1960; Tolman, 1955). Concepts of least effort would predict a preference for obtaining reinforcers freely-the result of most contrafreeloading studies, especially those using water as the reinforcer (e.g., Carder, 1972). However, this is not the result obtained when experimental conditions that differ only in terms of the variable of interest-dependence of reinforcer delivery upon responding-are pitted against one another.

\section{REFERENCE NOTES}

1. Walker, E. D., \& Grisham, M. G. Appetitive operant conditioning following response-independent delivery of the reinforcer: An interference effect. Paper presented at the meeting of the Midwestern Psychological Association, Chicago, May 1976.

2. Honig, W. K., \& Seraganian, P. Discrimination performance on a conceptual task with stimulus period duration controlled by the subject. Paper presented at the meeting of the Canadian Psychological Association, St. John's, Newfoundland, 1971.

3. Snapper, A. G., Stephens, K. R., \& Lee, D. M. The SKED software system. Kalamazoo, Mich: The SKED Users Group, Psychology Department, Western Michigan University, 1974.

\section{REFERENCES}

Autor, S. M. The strength of conditioned reinforcers as a function of the frequency and probability of reinforcement. In D. P. Hendry (Ed.), Conditioned reinforcement. Homewood, Ill: Dorsey Press, 1969.

Brinker, R. P., \& Treadway, J. T. Preference and discrimination between response-dependent and response-independent schedules of reinforcement. Journal of the Experimental Analysis of Behavior, 1975, 24, 73-77.

Carde R, B. Rats' preference for earned in comparison to free liquid reinforcers. Psychonomic Science, 1972, 26, 25-26.

Carder, B., \& Berkowitz, $K$. Rats' preference for earned in comparison with free food. Science, 1970, 167, 1273-1274.

D'Am Aтo, M. R. Derived motives. Annual Review of Psychology, 1974, 25, 83-106.

Grisham, M. G., \& Fret, L. J. An optically isolated digital interface for the SKED system. Behavior Research Methods \& Instrumentation, 1977, 9, 215-218.

Halliday, M. S., \& Boakes, R. A. Discrimination involving response-independent reinforcement: Implications for behavioral contrast. In R. A. Boakes \& M. S. Halliday (Eds.), Inhibition and learning. London: Academic Press, 1972.

Honig, W. K., \& BEALE, I. L. Stimulus duration as a measure of stimulus generalization. Journal of the Experimental Analysis of Behavior, 1976, 25, 209-217.

Honig, W. K., Beale, I., Seraganian, P., Lander, D., \& Muir, D. Stimulus and response reduction: Two aspects of inhibitory control in learning. In R. A. Boakes \& M. S. Halliday (Eds.), Inhibition and learning. London: Academic Press, 1972.

Honig, W. K., \& Lindsey, H. Transfer of a response controlling stimulus duration across discrimination problems. Learning and Motivation, 1975, 6, 157-178.

Hull, C. L. Principles of behavior. New York: Appleton-CenturyCrofts, 1943.

Jensen, G. D. Preference for barpressing over "freeloading" as a function of number of rewarded presses. Journal of Experimental Psychology, 1963, 65, 451-454.

Killeen, P. Response rate as a factor in choice. Psychonomic Science, 1968, 12, 34.

Leyland, C. M., \& Honig, W. K. Maintenance of behavior controlling the duration of discriminative stimuli. Journal of the Experimental Analysis of Behavior, 1975, 24, 207-214.

Logan, F. A. Incentive. New Haven: Yale University Press, 1960.

MoORE, J., \& Fantino, E. Choice and response contingencies. Journal of the Experimental Analysis of Behavior, 1975, 23. 339-348. 
Morgan, M. J. Do rats like to work for their food? Learning and Motivation, 1974, 5, 352-368.

Neuringe R, A. J. Delayed reinforcement versus reinforcement after a fixed interval. Journal of the Experimental Analysis of Behavior, 1969, 12, 375-383.

Osborne, S. R. The free food (contrafreeloading) phenomenon: A review and analysis. Animal Learning \& Behavior, 1977, 5, 221-235.

Siegel, R. K., \& Honig, W. K. Pigeon concept formation: Successive and simultaneous acquisition. Journal of the Experimental Analysis of Behavior, 1970, 13, 385-390.

SINGH, D. Preference for bar pressing to obtain reward over freeloading in rats and children. Journal of Comparative and Physiological Psychology, 1970, 73, 320-327.

SingH, D. Preference for mode of obtaining reinforcement in rats with lesions in septal or ventromedial hypothalamic area. Journal of Comparative and Physiological Psychology, 1972, 80, 259-268. (a)

Singh, D. The pied piper vs. the protestant ethic. Psychology Today, 1972, 5, 53-56. (b)

Singh, D., \& Query, W. T. Preference for work over "freeloading" in children. Psychonomic Science, 1971, 24, 77-79.

TAYLOR, G. A. A limitation of the contrafreeloading phenomenon. Psychonomic Science, 1972, 29, 173-174.

Tolman, E. C. Principles of performance. Psychological Review, $1955,62,315-326$.

(Received for publication July 28, 1978; revision accepted August 1, 1979.) 